\title{
Molecular Pathology: Predictive, Prognostic, and Diagnostic Markers in Tumors
}

Editor

LYNETTE M. SHOLL

\section{SURGICAL PATHOLOGY CLINICS}

www.surgpath.theclinics.com

Consulting Editor

JASON L. HORNICK

September 2016 • Volume 9 • Number 3 